\title{
Development of Food-Based Dietary Guidelines for Iran: A Preliminary Report
}

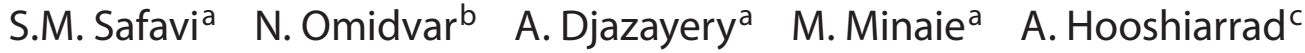 \\ R. Sheikoleslam ${ }^{\mathrm{a}}$ \\ a The Community Nutrition Department of the Ministry of Health and Medical Education, Tehran, Iran; \\ ${ }^{b}$ Department of Community Nutrition, School of Nutrition Sciences and Food Technology, Tehran, Iran, and \\ Iranian Nutrition Society (ATA); ' Department of Nutrition Research, National Nutrition and Food Technology \\ Research Institute, Tehran, Iran
}

\section{Key Words}

FBDGs · Iran, development of FBDGs · Nutrition education items). Three pictorial FBDGs were then designed: a plate, a pyramid, and a rectangle. Thus, three posters were prepared by the working teams and revised by a group of experts, followed by a preliminary evaluation. The final step will be field testing of the three revised, modified designs by the public and experts and their final evaluation.

Copyright $\odot 2007$ S. Karger AG, Basel

\section{Introduction}

The history of developing food-based dietary guidelines (FBDGs) in Iran dates back to the early 1960s, when the National Food and Nutrition Institute presented a poster showing the Four Basic Food Groups. In 1990, dietary guidelines, basically centered on food diversity, better methods of home food preparation, low salt and sugar intakes, breastfeeding, weight watching, and prevention of obesity were proposed and announced by the Iranian Nutrition Society [1]. The Society further revised the national food groups and dietary guidelines and included messages about physical activity. Recommendations were also made to adopt appropriate strategies to promote the nutritional awareness of the public.

Basically, food groups and dietary guidelines for any country - or even a region in a country - should be designed with due consideration of the prevailing health

\section{KARGER}

Fax +4161306 1234

E-Mail karger@karger.ch

www.karger.com
(C) $2007 \mathrm{~S}$. Karger AG, Basel

0250-6807/07/0518-0032\$23.50/0

Accessible online at:

www.karger.com/anm
N. Omidvar, Department of Community Nutrition

School of Nutrition Sciences and Food Technology

Shahid-Beheshti University of Medical Sciences

PO Box 19395/4741, Tehran (Iran)

Tel. +98 212236 0661, Fax +98212236 0660, E-Mail nomidvar@yahoo.com 
and nutrition situation, as well as of the socio-economic profile. Thus, before describing the process of developing the food groups and dietary guidelines, it will be appropriate to discuss briefly the health and nutrition situation in Iran.

As a result of lifestyle, food patterns, and socio-economic changes over the recent decades, Iran is undergoing nutrition transition $[2,3]$. Furthermore, successful health policies and programs have helped significantly in an increase in the life expectancy and promotion of public health. Disease patterns have changed. Studies show that diseases, such as diabetes mellitus, cancers, cardiovascular diseases, and obesity, have an increasing trend, while infectious diseases, although under control, are still problems. Another nutritional problem of great concern is micronutrient deficiencies. Sections of the population suffer from a deficiency, or at least a low intake of iron, vitamins $\mathrm{A}$ and $\mathrm{D}$, riboflavin, and calcium. Wasting and stunting are seen in some parts of the country [4]. On the other hand, all age/sex groups are at the risk of overweight and obesity due to a low level of regular physical activity and unsound food habits and nutritional behavior [5]. National food consumption surveys reveal that the staple food is cereals - mainly bread and rice. On the basis of the Food and Agriculture Organization and World Health Organization (FAO/WHO) [6] and the United States Department of Agriculture (USDA) [7] recommendations, the average daily intakes of animal products and pulses are low [8], oils and fats and simple sugar consumptions are on the increase, and the trend of animal products and pulses consumption is a downward one.

On the average, more than $50 \%$ of the daily energy and protein intakes are supplied by cereals [8]. The shares of animal products - which provide $35 \%$ of the daily intake of calcium and $55 \%$ of that of vitamin A - in supplying energy and protein are only 12 and $30 \%$, respectively. The mean per capita daily energy intake in both urban and rural areas exceeds $100 \%$.

\section{The Process}

The Nutrition Department of the Ministry of Health and Medical Education and the Iranian Nutrition Society (ATA) decided to prepare a food group plan and FBDGs for the Iranian population. In order to proceed systematically, groups of individuals with a wide range of expertise were formed, each charged with a specific task, with technical advice and support from nutritionists, food/ag- riculture scientists, epidemiologists, planners, and other related experts.

Firstly, information was collected on food consumption patterns, common nutrition-related diseases, cultural characteristics, and ease of access to foods in the community. Then a draft food group plan was designed and proposed with due consideration of the above factors and variables. The draft consisting of 7 food groups (Bread and Cereals, Meats and Eggs, Pulses, Vegetables, Fruits, Milk and Milk Products, and Miscellaneous) was commented by a group of food, nutrition and other experts. The comments and views were discussed in a meeting and changes were made. The revised draft was sent to another selected group of experts, followed by individual structured interviews with them. The final food group plan proposed by the team was as follows:

Group 1 - Bread and Cereals: all types of bread, rice, macaroni, wheat, barley

Group 2 - Meats and Eggs: all types of red meat, all types of white meat, eggs, shrimps

Group 3 - Pulses: all types of beans and peas, nuts

Group 4 - Vegetables: all types of leafy vegetables, all types of non-leafy vegetables

Group 5 - Fruits: apples, citrus fruit, grapes, other fruits

Group 6 - Milk and Milk Products: milk, yoghurt, cheese (other local dairy products)

Group 7 - Fats and Oils: all types of fats and oils, with emphasis on non-hydrogenated oils

Group 8 - Miscellaneous: sugars and sweets, salted and pickled products.

The next activity was development of FBDGs in the form of statements/sentences after thorough discussions and exchange of ideas. The FBDGs included statements/ sentences about the following topics: Selecting a balanced diet; maintenance of ideal body weight; regular exercise; increasing fiber intake through eating high-fiber food items; increasing intake of low-fat milk and milk products; decreasing solid fat intake by eating less fried foods; eating white meats, in preference to red meat, as far as possible; reducing salt and sugar intakes.

In the next step, it was decided to develop pictorial food groups and FBDGs. Literature search showed several pictorial representations of food groups and FBDGs - different with regard to color and design - currently in use in different countries. An important factor in deciding what design and color to use is evidently the cultural characteristics of a population/community [9]. The most commonly used designs were found to be the food pyramid [10], the pagoda (traditional multistorey 
Table 1. Food groups for the Iranian population, 2002

\begin{tabular}{ll}
\hline Group 1 & $\begin{array}{l}\text { Bread and Cereals: all types of bread, rice, pasta, } \\
\text { wheat, barley }\end{array}$ \\
Group 2 & $\begin{array}{l}\text { Vegetables: all types of leafy vegetables, and non-leafy } \\
\text { vegetables }\end{array}$ \\
Group 3 & $\begin{array}{l}\text { Fruits: apples, citrus fruit, grapes, other fruits } \\
\text { Group } 4\end{array}$ \\
Mroup 5 & $\begin{array}{l}\text { Mecal and Milk Products: milk, yoghurt, cheese, other } \\
\text { local } \\
\text { meat, all types of white meat, eggs, shrimps, all types } \\
\text { of pulses, nuts } \\
\text { Miscellaneous: fats and oils, sugars and sweets, salted } \\
\text { and pickled foods }\end{array}$ \\
Group 6
\end{tabular}

at determining their acceptability and understandability by representative samples of three groups of health and nutrition experts, health workers, and the public (mothers and local female health volunteers). Focus-group discussions and seminars were held for this purpose in several locations. Three posters were prepared based on the three designs agreed to - the pyramid, the plate, and the rectangle - and presented in actual sizes, and discussions were held. In addition, slide shows were given and the views and comments of the participants recorded. The final contents of the food group plan and the pictorial designs were prepared after analysis of the comments and views of the three groups. The pyramid was the design selected by the majority of the participants, followed by the plate and the rectangle.

\section{The Final Results}

The final food groups and FBDGs for the Iranian population are presented in tables 1 and 2, respectively. A final evaluation of the pictorial designs will be made subsequently before official declaration. It was agreed unanimously that the process of preparing the FBDGs is a dynamic process and that, therefore, continuous evaluation and revision is essential. It is recommended that these guidelines be revised every 5 years.

\section{Acknowledgements}

This project was funded by the World Health Organization Representative's Office in Tehran, Iran. Valuable contribution of the members of the Iranian Nutrition Society (ATA) and the Community Nutrition Department of the Ministry of Health and Medical Education, Tehran, in the conduct of the project is greatly acknowledged. Thanks are also extended to all the experts who participated in the focus-group discussions and meetings. We would also like to express our deep appreciation to all the health workers and mothers in the Health Centers who cooperated closely in this project.

house in the Far East) [11, 12], the food circle [9, 13, the plate [15], and the rainbow [16]. After thorough discussions, exchange of ideas, and technical consultations, and bearing in mind the most common cultural characteristics, pictorial food groups and FBDGs were designed to be field tested subsequently. The designers were professional ones briefed by the consultants. Agreement was reached on three designs - pyramid, plate, and rectangle - on the basis of which three posters were prepared.

This was followed by a preliminary evaluation and field testing of the food group plans and FBDGs aiming
1 Resolution of the First Iranian Nutrition Congress on The National Nutritional Problems, December 26-30, 1990, Tehran. Tehran, National Nutrition and Food Technology Research Institute, 1991.

2 Ghassemi H, Harrison G, Mohammad K, NourBalla AA: An accelerated nutrition transition in Iran. J Public Health Nutr 2002; 5:149-156.

\section{References}

Safavi/Omidvar/Djazayery/Minaie/ Hooshiarrad/Sheikoleslam 
3 Djazayery A, Pajooyan J: Food consumption patterns and nutritional problems in the Islamic Republic of Iran. Nutr Health 2000;14: 53-61.

4 MOHME (Ministry of Health and Medical Education)/UNICEF. The Nutritional Status of Children. October-November 1998. Tehran, MOHME/UNICEF, 1999.

5 Ghassemi H: Report on the 'National Food and Nutrition Security - A Planning and Administration Model' Project. Tehran, National Nutrition and Food Technology Research Institute/Plan and Budget Organization, 1999.

6 FAO/WHO: Diet, Nutrition and the Prevention of Chronic Diseases. Report of a Joint WHO/FAO Expert Consultation. WHO Tech Rep Ser 916. Geneva, WHO, 2003.
7 USDA, Center for Nutrition Policy and Promotion: The Food Guide Pyramid. Home Garden Bull 1996:252.

8 Kimiagar $\mathrm{M}$ et al: A comprehensive study on food intake and nutrition in Iran (in Farsi). National Nutrition and Food Technology Research Institute/Plan and Budget Organization, 1999.

9 Painter J, Rah JH, Lee YK: Comparison of international food guide pictorial presentations. J Am Diet Assoc 2002;102:483-489.

10 Orbeta SS: The Filipino Pyramid Food Guide. Nutr Today 1998;33:210-216.

11 Korean Nutrition Society: Recommended Dietary Allowances for Koreans, 7th Revision. Seoul, Jung-Ang Publishing, 2000.
12 The Chinese Nutrition Society: Dietary Guidelines and the Food Guide Pagoda. J Am Diet Assoc 2000;100:886-887.

13 Graca P: Dietary guidelines and food nutrient intakes in Portugal. Br J Nutr 1999; 81(suppl 2):S99-S103.

14 Hunt P, Rayner M, Gatenby S: A national food guide for the UK background and development. J Hum Nutr Diet 1995;8:315322 .

15 National Nutrition and Food Technology Research Institute: How to Eat to Be Healthy. Tehran, Ministry of Health and Medical education/National Nutrition and Food Technology Research Institute/UNICEF, 2001.

16 Canada's Food Guide to Healthy Eating. Ottawa, Health Canada, 1992. H39-252/1992E. Ministry of Public Works and Government Services Canada, 1997. ISBN 0-662-19648-1. 